\title{
Selection of industrial robot using axiomatic design principles in fuzzy environment
}

\author{
Anant V. Khandekar ${ }^{\mathrm{a}}$ and Shankar Chakraborty ${ }^{\mathrm{b} *}$
}

${ }^{a}$ Department of Mechanical Engineering, Government Polytechnic, Bandra (East), Mumbai - 400051, Maharashtra, India ${ }^{b}$ Department of Production Engineering, Jadavpur University, Kolkata - 700 032, West Bengal, India

\begin{tabular}{l}
\hline C H R O N I C L E \\
\hline Article history: \\
Received July 10, 2014 \\
Accepted December 31, 2014 \\
Available online \\
December 31 2014 \\
\hline Keywords: \\
Industrial robot \\
Axiomatic design principles \\
Fuzzy set theory \\
Information content
\end{tabular}

\section{Introduction}

An industrial robot is a man-made machine having artificial intelligence and can be programmed to dexterously carry out a variety of jobs. It also possesses certain anthropometrical features, and its mechanical arm is the most important and vital anthropometrical component. Other features, like its decision making capability, capacity of responding to various sensory inputs and communicating with other machines make it an important tool for diverse industrial applications (Chatterjee et al. 2010). The application domain of industrial robots comprises of welding, material handling, component assembling, painting, surface treatment and so on (Mondal \& Chakraborty, 2013). During the last half century, industrial robots have constantly been deployed in all manufacturing organizations worldwide. Generally, use of robots does not affect cost of raw materials, such as steel coils or castings that are purchased. Mainly, the application of industrial robots assists the manufacturing organizations in a dual * Corresponding author. Tel: +091-033-2414-6153

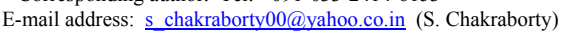

C) 2015 Growing Science Ltd. All rights reserved. doi: $10.5267 /$ j.ds1.2014.12.004 
manner as reducing the labour costs and increasing productivity (Glaser, 2008). A group of benefits achieved from implementing industrial robots also include enhanced operational precision, reduction in process changeover and lead time, maintained production capacity, capability to work in hazardous conditions and consistent quality output. Due to provision of all these benefits over the extended time periods, many varieties of industrial robots with different specifications and capabilities are now available for wide range of applications. Therefore, selection of an appropriate industrial robot for a given task becomes a difficult endeavour. It involves consideration of numerous attributes from diverse fields, like technical specifications, economic viability, environmental compatibility, availability and management policies. The nature of all these attributes is also contradictory to each other, thus making the selection procedure more tough and cumbersome. Bhangale et al. (2004) identified about 75 different attributes for selection of the best robot alternative for a given task, which could underline the complexity of a robot selection problem.

Until now, for solving robot selection problems, a number of mathematical approaches have been proposed by the past researchers. But as a part of the journey towards excellence, there is always a need for a simple and systematic tool to guide the decision makers in identifying and selecting the most suitable industrial robot from a given set of alternatives, because a wrong choice may often adversely affect the productivity and flexibility of the entire manufacturing process. There are a very few instances of axiomatic design (AD) principles being used for robot selection problem. Bahadir and Satoglu (2012) evaluated the performance of three robot alternatives with respect to axis speed, repeatability and investment cost while applying AD principles, wherein all the alternative ratings and criteria evaluation values were expressed in crisp form. In this paper, the applicability of fuzzy axiomatic design (FAD) principles is explored to evaluate the suitability of seven industrial robot alternatives with respect to nine criteria. Some of these criteria are of qualitative nature, whereas, the remaining criteria are expressed numerically. Using appropriate fuzzy scales for semantic as well as numerical range of data, all the robot alternatives are evaluated in terms of their total information content.

In this paper, the past literature on application of different multi-criteria decision-making (MCDM) methods for industrial robot selection is reviewed in Section 2. Concepts of fuzzy set theory and AD principles are explained in Section 3. Section 4 contains the methodology adopted for solving an industrial robot selection problem. A real time robot selection problem is solved in Section 5 to establish the potentiality of the adopted methodology. Finally, conclusions are drawn in Section 6.

\section{Literature review}

Bhangale et al. (2004) developed a reliable and exhaustive database of robot manipulators to standardize the robot selection procedure and help the robot users for selecting the most appropriate robot system to meet the operational requirements. Chatterjee et al. (2010) solved two robot selection problems using two MCDM methods, i.e. VIsekriterijumsko KOmpromisno Rangiranje (VIKOR) and ELimination and Et Choice Translating REality (ELECTRE). Kumar and Garg (2010) developed a deterministic quantitative model based on distance-based approach for evaluation, selection and ranking of robots. Athawale and Chakraborty (2011) compared the ranking performance of ten most popular MCDM methods while selecting the most appropriate robot for some industrial pick-n-place operation. It was concluded that for a given robot selection problem, more attention had to be given to proper selection of relevant criteria and alternatives, not on choosing the most appropriate MCDM method to be employed. Devi (2011) applied an extended VIKOR method for robot selection in intuitionistic fuzzy environment where the weights of criteria and ratings of the alternatives were considered as triangular intuitionistic fuzzy sets. Koulouriotis and Ketipi (2011) employed a fuzzy digraph method for robot evaluation and selection to meet the requirements of a given industrial application. For industrial robot selection, Rao et al. (2011) proposed a method that would consider the objective weights of importance of the attributes as well as subjective preferences of the decision 
maker to decide the integrated weights of importance of the attributes. Vahdani et al. (2011) presented a fuzzy modified technique for order preference by similarity to ideal solution (TOPSIS) for robot selection wherein the performance ratings of the alternatives with respect to various conflicting criteria as well as weights of the criteria were described using linguistic variables. İç (2012) explored the applicability of an integrated TOPSIS and design of experiment method to solve an industrial robot selection problem. Karsak et al. (2012) developed a decision model based on fuzzy linear regression for industrial robot selection and validated the derived results while comparing them with those obtained by the past researchers. Tao et al. (2012) presented a hybrid model for robot selection which had been consisted of three parts, i.e. a) data envelopment analysis (DEA) to provide the best combination on performance parameters, b) application of axiomatic fuzzy set theory and analytic hierarchy process to calculate the weight of each attribute, and c) TOPSIS method to provide the final ranking order. İç et al. (2013) developed a two-phase robot selection decision support system (ROBSEL) to help the decision makers in their robot selection decisions. Mondal and Chakraborty (2013) applied four models of DEA, i.e. Charnes, Cooper and Rhodes (CCR); Banker, Charnes and Cooper (BCC); additive; and cone-ratio to identify the feasible robots having the optimal performance measures. Vahdani et al. (2013) proposed an interval-valued fuzzy modified TOPSIS method for a robot selection problem wherein the performance ratings and weights of the criteria were linguistic variables expressed as triangular interval-valued fuzzy numbers. Alinezhad and Amini (2014) adopted a common weight maximin approach with an improved discriminating power for solving robot evaluation problems. Singh and Saha (2014) applied graph theory to select the most convenient robot among three alternatives for a given industrial application of packing and palletizing. Rashid et al. (2014) employed TOPSIS method wherein the opinions of several decision makers on different robot evaluation criteria for a set of alternatives were represented by generalized interval-valued trapezoidal fuzzy numbers. Vahdani et al. (2014) proposed an interval-valued fuzzy multi-criteria complex proportional assessment method for robot selection wherein the performance ratings with respect to various criteria as well as weights of the conflicting criteria were linguistically represented using interval-valued triangular fuzzy numbers. Yuen (2014) proposed the application of rectified fuzzy TOPSIS method, making use of compound linguistic ordinal scale as the fuzzy rating scale for expert judgments and cognitive pair-wise comparison for determining the fuzzy weights while addressing two robot selection problems. From this survey of literature related to industrial robot selection, it can be concluded that just within a span of 3 to 4 years, extensive work has been carried out in this field while using various MCDM techniques and tools. It shows the practical relevance of the topic of industrial robot selection and hence, it is quite befitting to explore the applicability of FAD principles to attend the robot selection problems.

\section{FAD principles}

Some of the commercial as well as technical specifications of industrial robots are stated more suitably in terms of linguistic terms and ranges of values. Hence, it is necessary to integrate fuzzy set theory concepts with AD principles as follows.

\subsection{Fuzzy set theory}

It is being observed that in day-to-day life, human beings are exposed to imprecise information more regularly than the quantum of precise information while taking real time decisions. Fuzzy set theory was introduced by Zadeh (1965) to deal with the uncertainty and imprecision related to information in an efficient manner to arrive at the logical conclusions in a more scientific manner. It is used to convert imprecise linguistic terms into numerical values using triangular or trapezoidal fuzzy numbers. Fuzzy logic has been proved to be an effective and robust tool for solving complex problems arising from a variety of fields, which include industrial applications too. 
Mathematically, fuzzy set theory states that in a universe of discourse $X$, a fuzzy subset $\tilde{A}$ of $X$ is defined by a membership function $f_{\widetilde{A}}(x)$, which maps each element $x$ in $X$ to a real number $R$ in unit interval of $[0,1]$. The function value $f_{\widetilde{A}}(x)$ represents the grade of membership of $x$ in $\widetilde{A}$. The larger the value of $f_{\widetilde{A}}(x)$, the stronger is the grade of membership for $x$ in $\widetilde{A}$. The fuzzy subset is designated as $\widetilde{A}=\left\{f_{\widetilde{A}}(x) / x \mid x \in X\right\}$.

Further, a fuzzy number $\tilde{A}$ is a triangular fuzzy number (TFN) if its membership function is represented as follows:

$$
f_{\tilde{A}}(x)=\left\{\begin{array}{cc}
(x-a) /(b-a) & a<x<b \\
1 & x=b \\
(x-c) /(b-c) & b<x<c \\
0 & \text { for all other cases }
\end{array}\right.
$$

Fig. 1 depicts the membership function of a TFN denoted by $(a, b, c)$.

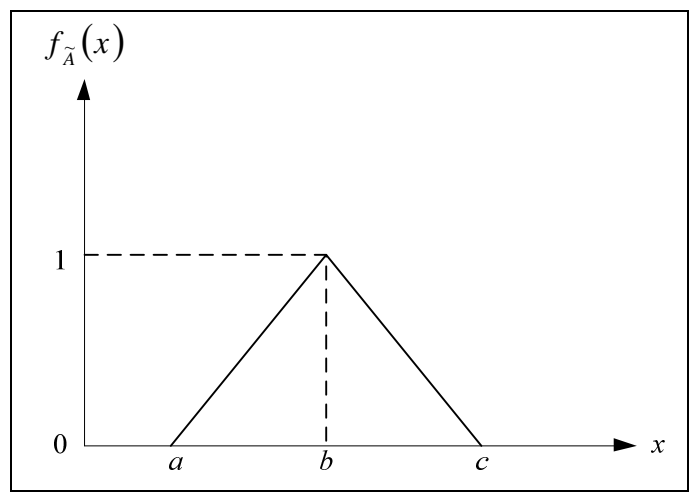

Fig. 1. Membership function for a TFN

\subsection{AD principles}

The concept of AD principles was proposed by Suh (1990) as a scientific and engineering approach for design of products. As a result, the design process has become more systematic and logical. It takes into consideration the customer needs related to a product to be incorporated in terms of functional requirements (FRs) and establishes the relation with the final design parameters (DPs) of the product. In the present context of decision-making, FRs represent various criteria with respect to which suitability of an alternative robot is to be judged for its intended function.

According to $\mathrm{AD}$ theory, the design process consists of some important steps as establishment of design goals to satisfy a given set of customer needs, conceptualization of design solutions, analysis of the proposed design solutions, selection of the best design solution from amongst those proposed and implementation of the selected solution. These steps occur in and between different design domains, such as customer domain, functional domain, physical domain and process domain, as illustrated in Figure 2. Customer domain consists of customer needs or attributes (CA) that the customer is looking for in a product or system to be designed. These customer needs are translated into a set of FRs and constraints in the functional domain. These FRs are then mapped into physical domain, where the DPs are conceived to satisfy the FRs. The DPs represent physical properties that define the design solution in the physical domain. The DPs are then mapped into process variables (PVs) in process domain. The PVs can generate the specified DPs. The process of mapping is the systematic way of synthesis and transformation of factors from previous to the next domain. 


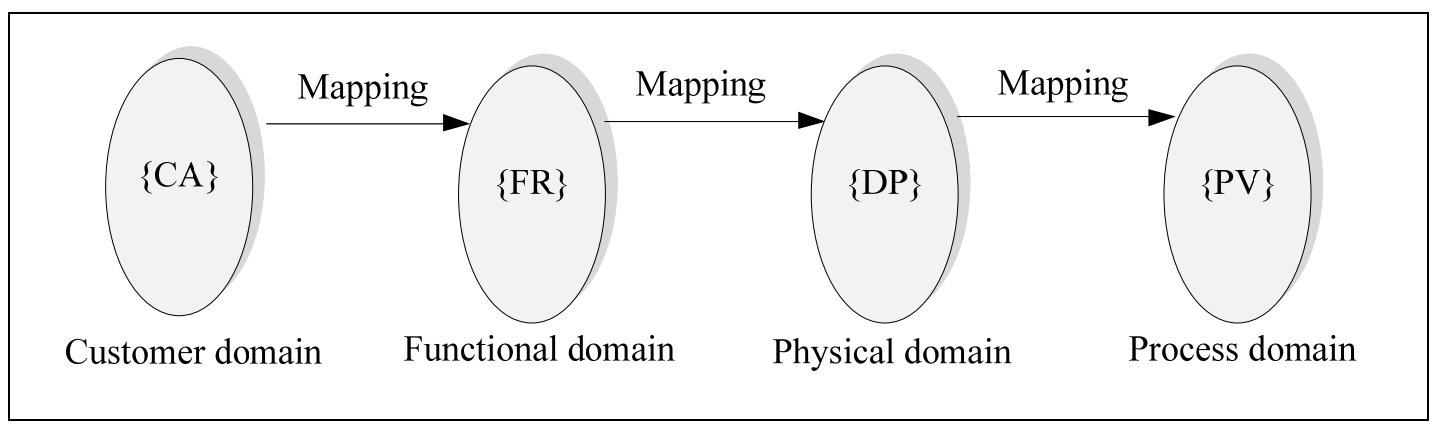

Fig. 2. Different design domains

In $\mathrm{AD}$ theory, the DPs are expressed in terms of range of values. Usually, this range is fixed by the designer or decision maker and is known as design range (DR). The values of FRs corresponding to various alternatives expressed by means of linguistic terms or numerical ranges or numerical approximations are known as system range (SR) values of the alternatives. In case of design of products, the designer has to choose the best design from different feasible solutions by the application of $\mathrm{AD}$ principles. This capability of $\mathrm{AD}$ theory of selecting the optimal design solution comes as a handy tool for decision-making. This task of decision-making is assisted by two underlying axioms of $\mathrm{AD}$ theory as stated below.

\subsubsection{Independence axiom}

Independence axiom states that a particular FR should be fulfilled independently by a certain DP without affecting the other FRs (Kulak, 2005). In real time situations too, a given complex design or a decision task is decomposed into smaller components and the independent solution for each of them is sought so as to simplify the process. So, the independence axiom is based on this analogy. In context of decision-making, shortlisting of different feasible alternatives for carrying out a designated task is the outcome of the application of independence axiom.

\subsubsection{Information axiom}

Under the preview of this axiom, information content (IC) is calculated for all the design solutions satisfying the independence axiom. Information axiom states that the alternative with minimum IC value is the optimal choice (Suh, 2001; Kulak, 2005). The IC is related in its simplest form to the probability of satisfying a given FR. It determines that the design with the highest probability of success is the best design. The $\mathrm{IC}_{i}$ value for a given $\mathrm{FR}_{i}$ is defined using the following equation:

$$
\mathrm{IC}_{i}=\log _{2}\left(\frac{1}{p_{i}}\right)
$$

where $p_{i}$ is the probability of satisfying FR ${ }_{i}$. The information is expressed in units of bits. The logarithmic function is chosen so that the IC values are additive when there are many FRs that must be satisfied simultaneously (Suh, 2001) and the logarithm is based on 2 which is the unit of bits. For the value of $p_{i}$ equal to zero, the IC value becomes infinite and the concerned alternative gets rejected. Conversely, for the value of $p_{i}$ equal to one, the IC value is zero and it is the ideal case of the selected alternative solution. The DR is decided by the designer or decision maker and it is the ideal range of values to be tried to achieve in the design process. The SR denotes the capability of the considered robot alternative for a particular FR. As shown in Fig. 3, the overlap between the designer-specified DR and the SR is known as 'common range' (CR), where the acceptable solutions exist. 


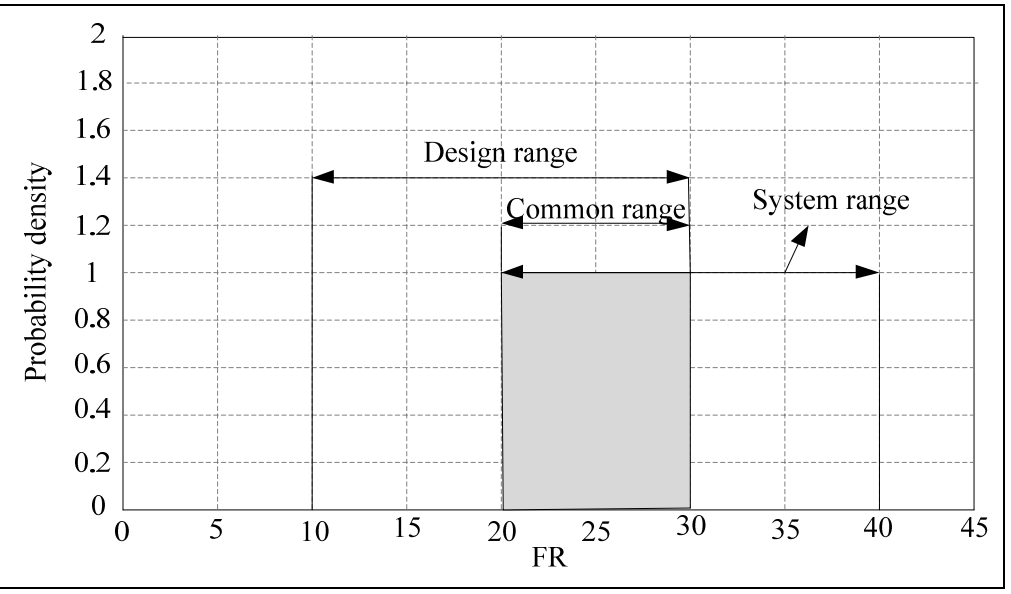

Fig. 3. Design range, system range and common range for FR

Therefore, in case of uniform probability distribution function, the value of $p_{i}$ is given as follows:

$$
p_{i}=\left(\frac{\mathrm{CR}}{\mathrm{SR}}\right)
$$

So, the value of IC can now be expressed as below:

$$
\mathrm{IC}_{i}=\log _{2}\left(\frac{\mathrm{SR}}{\mathrm{CR}}\right)
$$

If $\mathrm{FR}_{i}$ is a continuous random variable, as shown in Fig. 4 , then the probability of achieving $\mathrm{FR}_{i}$ in $\mathrm{DR}$ is given as:

$$
p_{i}=\int_{d r^{\prime}}^{d r^{u}} p_{s}\left(\mathrm{FR}_{i}\right) d \mathrm{FR}_{i},
$$

where $p_{s}\left(\mathrm{FR}_{i}\right)$ is the system probability density function (pdf) of $\mathrm{FR}_{i .} d r^{l}$ and $d r^{u}$ are the lower and upper bounds of DR. The probability of success is calculated by integrating the system pdf over the complete DR. In Figure 4, the area of system pdf over the common range $\left(A_{c r}\right)$ is equal to the probability of success $p_{i}$ (Suh, 1990). Therefore, the IC can be expressed as follows:

$$
\mathrm{IC}_{i}=\log _{2}\left(\frac{1}{\mathrm{~A}_{\mathrm{cr}}}\right),
$$

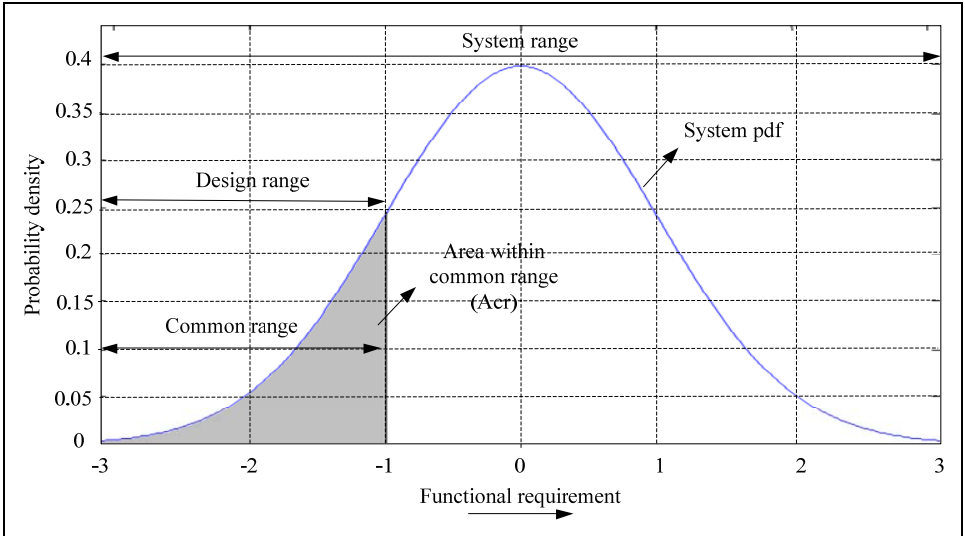

Fig. 4. Design range, system range, common range and system pdf for a FR (Celik et al., 2009) 


\section{Methodology based on FAD principles}

Fig. 5 shows the hierarchical structure developed for this industrial robot selection problem with respect to a set of nine conflicting criteria. For solving this problem based on FAD principles, the following procedural steps are proposed.

a) A five point fuzzy scale with triangular membership function is devised for rating the performance of the robot alternatives.

b) The total range of values for each criterion, whether quantitative or qualitative, is subdivided into five classes and they are assigned with appropriate values of fuzzy ratings. In case of beneficial criteria, these fuzzy ratings are assigned in ascending order of criteria values, whereas, for non-beneficial criteria, the reverse order is followed. For example, for payload capacity of a robot (a beneficial criterion), the fuzzy ratings of 'Poor' to 'Excellent' are assigned to range classes having minimum to maximum values respectively. On the other hand, for repeatability (a non-beneficial criterion), the fuzzy ratings of 'Poor' to 'Excellent' are assigned to range classes having maximum to minimum values respectively.

c) Another fuzzy scale is devised for assigning DR values to the considered criteria.

d) Total IC values are calculated for all the industrial robot alternatives.

e) Finally, the robot alternatives are ranked in the order of their ascending values of total IC and the most appropriate robot for the given application is identified.

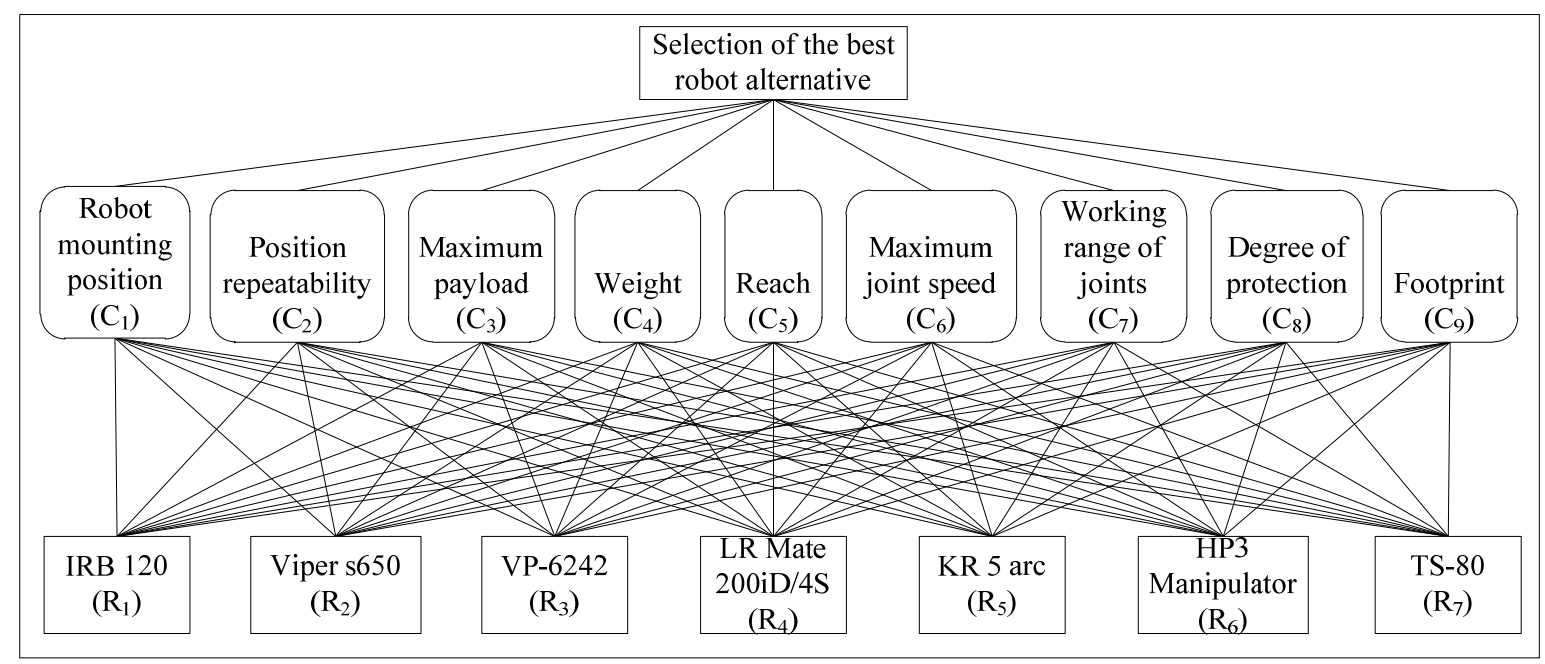

Fig. 5. Hierarchy for industrial robot selection problem

\section{Illustrative example}

For efficiently carrying out light assembly operations in a manufacturing organization, seven types of commercially available industrial robots are first shortlisted. In order to accomplish the desired assembly task, nine important attributes are then identified for each robot alternative. The technical specifications of all the robot alternatives are accumulated from various robot manufacturers' websites, like http://www.abb.com/robotics, http://adept.com, http://www.densorobotics.com, http://www.fanuc.co.jp, http://www.kuka-robotics.com, http://motoman.com, http://indutrial. panasonic.com/eu/, http://www.staubli.com/robotics etc. Table 1 provides the corresponding decision matrix for this industrial robot selection problem. In AD parlance, it is the SR data of the industrial robot alternatives. The nine attributes considered are robot mounting position, position repeatability (in $\mathrm{mm}$ ), maximum payload (in $\mathrm{kg}$ ), weight (in $\mathrm{kg}$ ), reach (in $\mathrm{mm}$ ), maximum joint speed (in degree/s), working range of joints (in degree), degree of protection and footprint (in $\mathrm{cm}^{2}$ ). Mounting position represents the ability of a robot to fasten it securely on a given surface during the working cycle, while position repeatability is articulated as how well a robot can come back to a programmed location and 
orientation over and over again. Payload indicates the maximum weight (load) a robot can pick up without affecting its performance and weight denotes the self weight of the robot. Reach of a robot is the maximum distance that can be covered so as to grasp an object for an assembly operation, while joint speed is defined as how quickly a robot can position its arm/actuator. Working range represents the manoeuvrability of the end effectors. Degree of protection denotes the protection provided by an enclosure against access to hazardous parts, ingress of solid foreign objects and water. This protective ability of the enclosure is expressed in terms of International Protection (IP) codes. The IP code consists of two numerals and two optional extra letters. The first numeral $0,1, \ldots, 6$, or X defines the protection against ingress of solid foreign objects and against access to hazardous parts. The second numeral 0 , $1, \ldots, 8$, or $\mathrm{X}$ defines the protection against the ingress of water. The higher the number, the more stringent is the protection requirement. Footprint is the amount of space required for installing a robot.

Amongst the considered nine attributes, two criteria, i.e. robot mounting position and degree of protection are expressed qualitatively and others are expressed numerically. It can also be noted that almost all these seven quantitative attributes are stated in terms of range of values. Therefore, in order to uniformly express all these FRs, a five point fuzzy scale with ratings as poor, fair, good, very good and excellent is considered (Büyüközkan \& Ersoy, 2009). Six attributes as robot mounting position, maximum payload, reach, maximum joint speed, working range of joints and degree of protection are beneficial criteria for which higher values are always desired. The remaining three criteria, i.e. position repeatability, weight and footprint are non-beneficial criteria for which lower values are preferred. So, taking into account the type of the criteria, the SR data corresponding to all the attributes are divided into five range classes of the considered fuzzy scale and their membership functions in terms of TFNs are shown in Table 2. Now, considering the membership functions of SRs from Table 2, the heterogeneous SR data of this robot selection problem as depicted in Table 1 are fuzzified in Table 3 . The DRs of the criteria are also expressed in terms of TFNs. The five point fuzzy scale for DR is developed as 'At least poor' (LP) - $(0,1,1)$, 'At least fair' (LF) - $(0.1,1,1)$, 'At least good' (LG) - $(0.4$, $1,1)$, 'At least very good' (LVG) - $(0.6,1,1)$ and 'At least excellent' (LE) - $(0.8,1,1)$, and is shown in Fig. 6 (Büyüközkan \& Ersoy, 2009). As a decision maker, the design ratings for the nine FRs of robot mounting position, position repeatability, maximum payload, weight, reach, maximum joint speed, working range of joints, degree of protection and footprint are chosen as LG, LG, LG, LG, LF, LF, LG, LG and LG respectively.

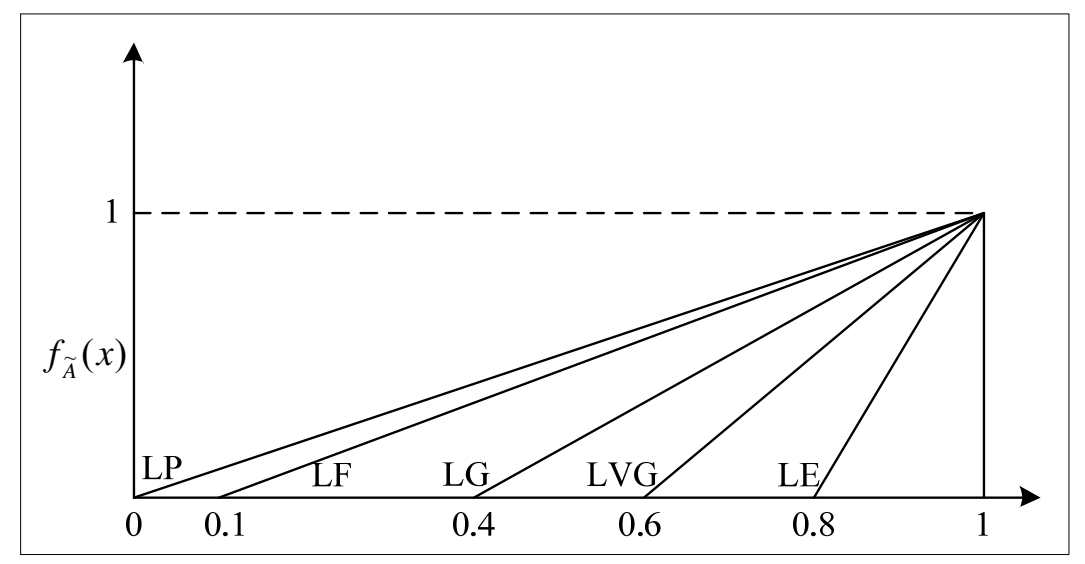

Fig. 6. Fuzzy scale for DR

The total IC value for each robot alternative is the summation of individual IC values corresponding to its all nine FRs. As a representative case, the calculation of IC value of robot alternative $\mathrm{R}_{2}$ for FR of mounting position is demonstrated here. The design rating for FR of mounting position is 'At least good' with TFN as $(0.4,1.0,1.0)$ and the SR of mounting position for alternative $\mathrm{R}_{2}$ is 'Very good' with TFN as $(0.6,0.75,0.9)$. In Fig. 7 , the triangles ABC and PQR represent the TFNs of SR and DR respectively. 


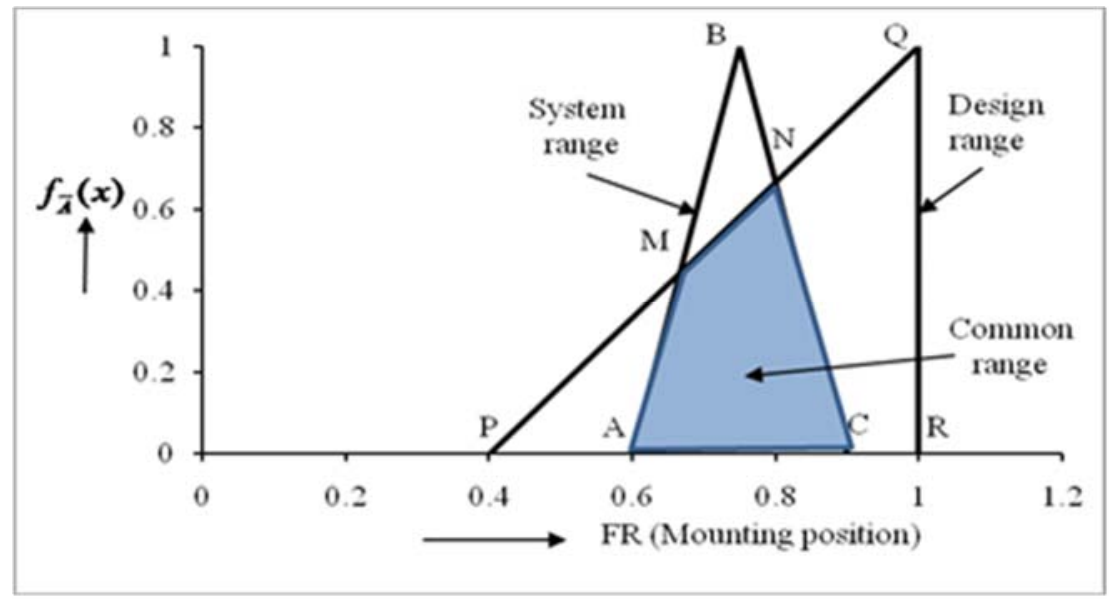

Fig. 7. Design range, system range and common range for mounting position of $\mathrm{R}_{2}$

Table 1

System range data

\begin{tabular}{|c|c|c|c|c|c|c|c|c|c|}
\hline \multirow{2}{*}{ Robot alternative } & \multicolumn{9}{|c|}{ Criteria } \\
\hline & $\mathrm{C}_{1}$ & $\mathrm{C}_{2}$ & $\mathrm{C}_{3}$ & $\mathrm{C}_{4}$ & $\mathrm{C}_{5}$ & $\mathrm{C}_{6}$ & $\mathrm{C}_{7}$ & $\mathrm{C}_{8}$ & $\mathrm{C}_{9}$ \\
\hline IRB $120\left(\mathrm{R}_{1}\right)$ & Required position & \pm 0.01 & 3 & 25 & 580 & 420 & \pm 400 & IP30 & 324 \\
\hline Viper s650 $\left(\mathrm{R}_{2}\right)$ & Floor, table and ceiling & \pm 0.02 & 5 & 28 & 653 & 600 & \pm 360 & IP65 & 400 \\
\hline VP-6242 $\left(\mathrm{R}_{3}\right)$ & Floor and ceiling & \pm 0.02 & 2.5 & 15 & 432 & 550 & \pm 360 & IP54 & 256 \\
\hline LR Mate $200 \mathrm{iD} / 4 \mathrm{~S}\left(\mathrm{R}_{4}\right)$ & Floor and ceiling & \pm 0.02 & 4 & 20 & 550 & 900 & \pm 720 & IP68 & 256 \\
\hline $\mathrm{KR} 5 \operatorname{arc}\left(\mathrm{R}_{5}\right)$ & Floor and ceiling & \pm 0.04 & 5 & 127 & 1412 & 721 & \pm 350 & IP54 & 1050 \\
\hline HP3 Manipulator $\left(\mathrm{R}_{6}\right)$ & Floor, table and ceiling & \pm 0.03 & 3 & 45 & 701 & 500 & \pm 360 & IP45 & 484 \\
\hline $\mathrm{TS}-80\left(\mathrm{R}_{7}\right)$ & Floor and wall & \pm 0.01 & 8 & 55 & 800 & 2020 & \pm 500 & IP54 & 438 \\
\hline
\end{tabular}

Table 2

Membership functions for system range

\begin{tabular}{|c|c|c|c|c|c|c|}
\hline Rating & TFN & Robot mounting position & Position repeatability & Maximum payload $(\mathrm{m})$ & Weight $(w)$ & Reach $(r)$ \\
\hline Poor (P) & $(0,0,0.3)$ & Floor only & \pm 0.05 & $0<m<2$ & $w>55$ & 400 to 500 \\
\hline Fair (F) & $(0.2,0.35,0.5)$ & Floor and wall & \pm 0.04 & $2 \leq m<4$ & 46 to 55 & 501 to 600 \\
\hline Good (G) & $(0.4,0.55,0.7)$ & Floor and ceiling & \pm 0.03 & $4 \leq m<6$ & 36 to 45 & 601 to 700 \\
\hline Very good (VG) & $(0.6,0.75,0.9)$ & Floor, table and Ceiling & \pm 0.02 & $6 \leq m<8$ & 26 to 35 & 701 to 800 \\
\hline Excellent (E) & $(0.8,1,1)$ & Required position & \pm 0.01 & $8 \leq m<10$ & 15 to 25 & $r>800$ \\
\hline
\end{tabular}

Table 2

Membership functions for system range (Cont.)

\begin{tabular}{cccccc}
\hline Rating & TFN & Maximum joint speed $(s)$ & Working range of joints $(j r)$ & Degree of protection & Footprint $(f p)$ \\
\hline Poor (P) & $(0,0,0.3)$ & $s \leq 525$ & $j r \leq( \pm 350)$ & IP20 to IP28 & fp $>550$ \\
Fair (F) & $(0.2,0.35,0.5)$ & $525<s \leq 650$ & $( \pm 351)$ to $( \pm 450)$ & IP30 to IP38 & 476 to 550 \\
Good (G) & $(0.4,0.55,0.7)$ & $650<s \leq 775$ & $( \pm 451)$ to $( \pm 550)$ & IP40 to IP48 & 401 to 475 \\
Very good (VG) & $(0.6,0.75,0.9)$ & $775<s \leq 900$ & $( \pm 551)$ to $( \pm 650)$ & IP50 to IP58 & 326 to 400 \\
Excellent (E) & $(0.8,1,1)$ & $s>900$ & $j r>( \pm 650)$ & IP60 to IP68 & 250 to 325 \\
\hline
\end{tabular}

Table 3

System range data in qualitative terms

\begin{tabular}{cccccccccc}
\hline Robot alternative & & & & & Criteria & & & $\mathrm{C}_{8}$ & $\mathrm{C}_{9}$ \\
\hline $\mathrm{R}_{1}$ & $\mathrm{C}_{1}$ & $\mathrm{C}_{2}$ & $\mathrm{C}_{3}$ & $\mathrm{C}_{4}$ & $\mathrm{C}_{5}$ & $\mathrm{C}_{6}$ & $\mathrm{C}_{7}$ & $\mathrm{C}_{8}$ & $\mathrm{E}$ \\
$\mathrm{R}_{2}$ & $\mathrm{E}$ & $\mathrm{E}$ & $\mathrm{F}$ & $\mathrm{E}$ & $\mathrm{F}$ & $\mathrm{P}$ & $\mathrm{F}$ & $\mathrm{F}$ & $\mathrm{VG}$ \\
$\mathrm{R}_{3}$ & $\mathrm{G}$ & $\mathrm{VG}$ & $\mathrm{G}$ & $\mathrm{VG}$ & $\mathrm{G}$ & $\mathrm{F}$ & $\mathrm{F}$ & $\mathrm{F}$ & $\mathrm{E}$ \\
$\mathrm{R}_{4}$ & $\mathrm{G}$ & $\mathrm{VG}$ & $\mathrm{F}$ & $\mathrm{E}$ & $\mathrm{P}$ & $\mathrm{F}$ & $\mathrm{F}$ & $\mathrm{V}$ & $\mathrm{E}$ \\
$\mathrm{R}_{5}$ & $\mathrm{G}$ & $\mathrm{F}$ & $\mathrm{G}$ & $\mathrm{E}$ & $\mathrm{F}$ & $\mathrm{VG}$ & $\mathrm{E}$ & $\mathrm{E}$ & $\mathrm{P}$ \\
$\mathrm{R}_{6}$ & $\mathrm{VG}$ & $\mathrm{G}$ & $\mathrm{F}$ & $\mathrm{P}$ & $\mathrm{E}$ & $\mathrm{G}$ & $\mathrm{P}$ & $\mathrm{VG}$ & $\mathrm{P}$ \\
$\mathrm{R}_{7}$ & $\mathrm{~F}$ & $\mathrm{E}$ & $\mathrm{E}$ & $\mathrm{F}$ & $\mathrm{VG}$ & $\mathrm{P}$ & $\mathrm{F}$ & $\mathrm{G}$ & $\mathrm{F}$ \\
& & & & & & $\mathrm{E}$ & $\mathrm{G}$ & $\mathrm{VG}$ & $\mathrm{G}$ \\
\hline
\end{tabular}


Table 4

Total IC and ranking of robot alternatives

\begin{tabular}{|c|c|c|c|c|c|c|c|c|c|c|c|}
\hline \multirow{2}{*}{$\begin{array}{c}\text { Robot } \\
\text { alternative }\end{array}$} & \multicolumn{9}{|c|}{ Information content } & \multirow{2}{*}{ Total IC } & \multirow{2}{*}{ Rank } \\
\hline & $\mathrm{C}_{1}$ & $\mathrm{C}_{2}$ & $\mathrm{C}_{3}$ & $\mathrm{C}_{4}$ & $\mathrm{C}_{5}$ & $\mathrm{C}_{6}$ & $\mathrm{C}_{7}$ & $\mathrm{C}_{8}$ & $\mathrm{C}_{9}$ & & \\
\hline $\mathrm{R}_{1}$ & 0 & 0 & 4.4919 & 0 & 1.1094 & 3.1699 & 4.4919 & 4.4919 & 0 & 17.755 & 5 \\
\hline $\mathrm{R}_{2}$ & 0.2955 & 0.2955 & 1.3219 & 0.2955 & 0.4288 & 1.1094 & 4.4919 & 0 & 0.2955 & 8.534 & 2 \\
\hline $\mathrm{R}_{3}$ & 1.3219 & 0.2955 & 4.4919 & 0 & 3.1699 & 1.1094 & 4.4919 & 0.2955 & 0 & 15.176 & 4 \\
\hline $\mathrm{R}_{4}$ & 1.3219 & 0.2955 & 1.3219 & 0 & 1.1094 & 0.1193 & 0 & 0 & 0 & 4.168 & 1 \\
\hline $\mathrm{R}_{5}$ & 1.3219 & 4.4919 & 1.3219 & INFINITE & 0 & 0.4288 & INFINITE & 0.2955 & INFINITE & INFINITE & 7 \\
\hline $\mathrm{R}_{6}$ & 0.2955 & 1.3219 & 4.4919 & 1.3219 & 0.1193 & 3.1699 & 4.4919 & 1.3219 & 4.4919 & 21.0261 & 6 \\
\hline $\mathrm{R}_{7}$ & 4.4919 & 0 & 0 & 4.4919 & 0.1193 & 0 & 1.3219 & 0.2955 & 1.3219 & 12.0424 & 3 \\
\hline
\end{tabular}

The co-ordinates of points $\mathrm{M}$ and $\mathrm{N}$ are determined as $(0.6667,0.4444)$ and $(0.8,0.6667)$ respectively. The area of triangle ABC is calculated to be 0.15 sq units and it is the SR area. The common area of intersection between SR and DR is the area of the quadrangle AMNC, and is computed as $0.1222 \mathrm{sq}$ units. Therefore, using Eqn. (4), the IC value is determined as below for mounting position criterion of robot $\mathrm{R}_{2}$.

$$
\mathrm{IC}_{\mathrm{R}_{2}-\mathrm{C}_{1}}=\log _{2}\left(\frac{S R}{C R}\right)=\log _{2}\left(\frac{0.15}{0.1222}\right)=0.2955
$$

Similarly, the IC values of all the robot alternatives for each criterion are computed and are provided in Table 4 . For robot $\mathrm{R}_{1}$, the SR and DR of mounting position are $(0.8,1,1)$ and $(0.4,1,1)$ respectively. Therefore, SR equals to $\mathrm{CR}$ and hence, the IC value becomes equal to zero. For robot alternative $\mathrm{R}_{5}$, there is no common area of intersection between SR and DR for criterion of weight, resulting in the IC value to be infinite.

All the individual IC values of nine criteria are added together to derive the total IC value for each robot alternative, as shown in Table 4. Then, based on the information axiom of AD principles, these industrial robot alternatives are ranked in ascending order of their total IC values. As a result, $\mathrm{R}_{4-} \mathrm{R}_{2}-$ $\mathrm{R}_{7}-\mathrm{R}_{3}-\mathrm{R}_{1}-\mathrm{R}_{6}-\mathrm{R}_{5}$ evolves out as the order of suitability of the robot alternatives, with LR Mate $200 \mathrm{iD} / 4 \mathrm{~S}$ $\left(\mathrm{R}_{4}\right)$ as the best choice and KR 5 arc $\left(\mathrm{R}_{5}\right)$ as the worst choice for the intended task of light assembly operations.

\section{Conclusions}

Nowadays, in almost all the manufacturing organizations, the application area of robots is rapidly increasing. Use of industrial robots is dictated by various factors, like need for higher precision, speed and safety in manufacturing operations. As a natural consequence, many varieties of robots are now available in the commercial market for a given industrial task. Therefore, selection of the most suitable robot with respect to numerous conflicting criteria of qualitative and quantitative nature becomes a more challenging and difficult problem. This paper proposes the application of FAD principles for selection of the best suited industrial robot from a group of equally competitive seven feasible alternatives for light assembly operations. This methodology is proved to be quite efficient in selecting LR Mate $200 \mathrm{iD} / 4 \mathrm{~S}$ as the most appropriate choice. The derived result seems to be well validated, when it is viewed from the perspective of the capabilities of the given robot alternatives and nature of the designated task. The beneficial aspect of this methodology is that it selects the robot alternative which mostly satisfies the DR values for the assigned task. It is also quite easy to apply and comprehend. But, this methodology cannot select a robot alternative if the IC value of any one of the criteria is 'infinitive' even if it meets the DRs of all other criteria successfully. As a result, it is not possible to evaluate how much this alternative deviates from the designed requirement because of its 'infinitive' total IC value. 


\section{References}

Athawale, V.M., \& Chakraborty, S. (2011). A comparative study on the ranking performance of some multi-criteria decision-making methods for industrial robot selection, International Journal of Industrial Engineering Computations, 2(4), 831-850.

Alinezhad, A., \& Amini, M. (2014). Practical common weight maxmin approach for technology selection. Journal of Fundamental and Applied Sciences, 6(1), 31-47.

Bahadir, M.C., \& Satoglu, S.I. (2012). A decision support system for robot selection based on axiomatic design principles. Proc. Int. Conf. on Industrial Engineering and Operations Management, Turkey, 674-683.

Bhangale, P.P., Agrawal, V.P., \& Saha, S.K. (2004). Attribute based specification, comparison and selection of a robot. Mechanism and Machine Theory, 39(12), 1345-1366.

Büyüközkan, G. \& Ersoy, M. Ş. (2009). Applying fuzzy decision making approach to IT outsourcing supplier selection. World Academy of Science, Engineering and Technology, 3(7), 382-386.

Celik, M., Kahraman,C., Cebi, S. \& Er, I.D. (2009). Fuzzy axiomatic design-based performance evaluation model for docking facilities in shipbuilding industry: The case of Turkish shipyards. Expert Systems with Applications, 36(1), 599-615.

Chatterjee, P., Athawale, V.M., \& Chakraborty, S. (2010). Selection of industrial robots using compromise ranking and outranking methods. Robotics and Computer-Integrated Manufacturing, 26(5), 483-489.

Devi, K. (2011). Extension of VIKOR method in intuitionistic fuzzy environment for robot selection. Expert Systems with Applications, 38(11), 14163-14168.

Glaser, A. (2008). Industrial Robotics: How to Implement the Right System for Your Plant Automation. New York, Industrial Press, Inc.

İç, Y.T. (2012). An experimental design approach using TOPSIS method for the selection of computerintegrated manufacturing technologies. Robotics and Computer-Integrated Manufacturing, 28(2), 245-256.

İç, Y.T., Yurdakul, M., \& Dengiz, B. (2013). Development of a decision support system for robot selection. Robotics and Computer-Integrated Manufacturing, 29(4), 142-157.

Karsak, E.E., Sener, Z., \& Dursun, M. (2012). Robot selection using a fuzzy regression-based decisionmaking approach. International Journal of Production Research, 50(23), 6826-6834.

Koulouriotis, D.E., \& Ketipi, M.K. (2011). A fuzzy digraph method for robot evaluation and selection. Expert Systems with Applications, 38(9), 11901-11910.

Kulak, O. (2005). A decision support system for fuzzy multi-attribute selection of material handling equipments. Expert Systems with Applications, 29(2), 310-319.

Kumar, R., \& Garg, R.K. (2010). Optimal selection of robots by using distance based approach method. Robotics and Computer-Integrated Manufacturing, 26(5), 500-506.

Mondal, S., \& Chakraborty, S. (2013). A solution to robot selection problems using data envelopment analysis. International Journal of Industrial Engineering Computations, 4(3), 355-372.

Rao, R.V., Patel, B.K., \& Parnichkun, M. (2011). Industrial robot selection using a novel decision making method considering objective and subjective preferences. Robotics and Autonomous Systems, 59(6), 367-375.

Rashid, T., Beg, I., \& Husnine, S.M. (2014). Robot selection by using generalized interval-valued fuzzy numbers with TOPSIS. Applied Soft Computing, 21, 462-468.

Singh, A., \& Saha, R. (2014). Selection and comparison of industrial robots for packaging and palletizing using graph theory. International Journal of Applied Engineering Research, 9(5), 505509.

Suh, N.P. (1990). The Principles of Design. Oxford University Press, New York.

Suh, N.P. (2001). Axiomatic Design: Advances and Applications. Oxford University Press, New York.

Tao, L., Chen, Y., Liu, X., \& Wang, X. (2012). An integrated multiple criteria decision making model applying axiomatic fuzzy set theory. Applied Mathematical Modelling, 36(10), 5046-5058. 
Vahdani, B., Mousavi, S.M., \& Tavakkoli-Moghaddam, R. (2011). Group decision making based on novel fuzzy modified TOPSIS method. Applied Mathematical Modelling, 35(9), 4257-4269.

Vahdani, B., Tavakkoli-Moghaddam, R., Mousavi, S.M., \& Ghodratnama, A. (2013). Soft computing based on new interval-valued fuzzy modified multi-criteria decision-making method. Applied Soft Computing, 13(1), 165-172.

Vahdani, B., Mousavi, S.M., Tavakkoli-Moghaddam, R., Ghodratnama, A., \& Mohammadi, M. (2014). Robot selection by a multiple criteria complex proportional assessment method under an intervalvalued fuzzy environment. International Journal of Advanced Manufacturing Technology, 73(5-8), 687-697.

Yuen, K.K.F. (2014). Combining compound linguistic ordinal scale and cognitive pair wise comparison in the rectified fuzzy TOPSIS method for group decision making. Fuzzy Optimization and Decision Making, 13(1), 105-130.

Zadeh. L.A. (1965). Fuzzy sets. Information and Control, 8(3), 338-353. 